\title{
PERAN SUPERVISI -KEPALA SEKOLAH \\ DALAM PENINGKATAN KINERJA GURU SMK SANTO YUSUP - BLITAR
}

\author{
Vincentius Prastowo \\ prastbegood@gmail.com
}

\begin{abstract}
The research is aimed at knowing the role of supervision of the principal in the effort of upgrading the performance of the teacher at Vocational Middle School St. Joseph Blitar. The research uses the qualitative approach, with the method of the case study of Robert K. Yin with six steps of the research: plan, design, prepare, collect, analyze, and share. The act of determining the source in this research uses purposive sampling. The technique of gathering data uses three methods: interview, observation and study documentation. The result of the research shows that: first, the carrying out of the diagnosis with regards to the problem of teaching of the teachers at Vocational Middle School St. Joseph Blitar could be seen by (a) gathering data of the performance of the teachers, (b) breaking down into its parts the problem of the performance of the teachers,(c) making the criteria for the conclusion. Second, the improvement of the teaching of the teachers at Vocational Middle School St. Joseph Blitar can be seen from (a) preparing an alternative solution to the problem of the performance of teachers, (b) evaluating the strength and weakness of each of the alternative solution the problem, (c) making the recommendation. Third, formation as a continuous measure to solve the problem of the teaching of the teachers can be seen from (a) applying the decision, (b) monitoring, (c) evaluation of the implementation of the decision.
\end{abstract}

Key words: Principal; Supervision; Teacher Performance

Abstrak: Penelitian ini bertujuan untuk mengetahui peran pengawasan kepala sekolah dalam upaya meningkatkan kinerja guru di SMK St. Joseph - Blitar. Peneliti menggunakan pendekatan kualitatif, dengan metode studi kasus Robert K. Yin dengan enam langkah penelitian yaitu: merencanakan, merancang, mempersiapkan, mengumpulkan, menganalisis, dan berbagi. Tindakan menentukan sumber dalam penelitian ini menggunakan purposive sampling. Teknik pengumpulan data menggunakan tiga metode: wawancara, observasi dan studi dokumentasi. Hasil penelitian menunjukkan bahwa: pertama, pelaksanaan diagnosis masalah pengajaran guruguru SMK St. Yusup Kota Blitar dapat dilihat dengan adanya proses: (a) mengumpulkan data dari kinerja guru, (b) pemetaan masalah kinerja guru, (c) merumuskan masalah dan penyebab masalah kinerja guru. Kedua, perbaikan permasalahan mengajar guru-guru SMK St. Yusup Blitar dapat dilihat dari: (a) menyiapkan solusi alternatif untuk masalah mengajar guru, (b) mengevaluasi kekuatan dan kelemahan solusi alternative, (c) membuat rekomendasi. Ketiga, langkah pembinaan untuk menyelesaikan masalah mengajar guru dapat dilihat dari: (a) menerapkan keputusan program pembinaan, (b) pemantauan program pembinaan, (c) evaluasi pelaksanaan program pembinaan.

Kata kunci: Kepala sekolah, Supervisi, Kinerja Guru

\section{PENDAHULUAN}

Mutu sekolah, secara esensial, berkaitan dengan supervisi kepala sekolah sebagai pimpinan sekolah terhadap guru yang ada di sekolah. Dalam konteks otonomi sekolah, kepala sekolah memiliki kewenangan yang besar dalam membuat kebijakan di tingkat sekolah, melaksanakan, dan mengawasinya, supaya sekolah yang dipimpinnya memiliki kemampuan untuk mengembangkan potensi yang ada di sekolah. Kepala sekolah sebagai penanggung jawab pendidikan pada tingkat sekolah, memiliki kewenangan dan keleluasaan dalam mengembangkan 
berbagai program sekolah, mengelola, dan mengawasinya. Kepala sekolah memiliki keleluasaan dalam mengatur segenap sumber daya sekolah yang ada, yang dapat dimanfaatkan sebesarbesarnya bagi peningkatan mutu dan kinerja sekolah. Aktivitas pengarahan, bimbingan, dan pengawasan yang dilakukan oleh kepala sekolah kepada guru, staf, dan pegawai lainnya disebut sebagai supervisi.

Tidak bisa dipungkiri bahwa tujuan pendidikan di sekolah memerlukan kerjasama dari semua pihak, yaitu dari sekolah, orang tua, masyarakat, dan pemerintah. Namun demikian ujung tombak dalam mencapai tujuan Pendidikan di sekolah adalah para guru. Maka kepala sekolah sebagai penanggung jawab berlangsungnya proses pendidikan di sekolah harus selalu membantu menjaga dan mengembangkan kinerja guru secara terencana dan terus menerus sehingga tujuan pendidikan dapat tercapai dengan baik.

Kinerja guru atau teacher performance dalam konteks pendidikan di sekolah adalah hasil kerja atau output dari empat kompetensi utama guru, yaitu kompetensi pedagogik, kompetensi kepribadian, kompetensi sosial, dan kompetensi profesional. Seorang guru diharapkan tidak hanya memiliki kemampuan teknis edukatif saja, tetapi juga harus menunjukkan kepribadian yang dapat diandalkan sehingga menjadi sosok panutan bagi peserta didik, keluarga maupun masyarakat. Guru sebagai pendidik berarti ia adalah penerus dan pengembang nilai-nilai hidup, mengajar berarti meneruskan dan mengembangkan ilmu pengetahuan dan teknologi, dan melatih berarti mengembangkan keterampilan-keterampilan peserta didik. Guru juga harus mampu menunjukkan perannya sebagai orangtua kedua bagi para peserta didik, mampu memotivasi peserta didik dalam belajar. Guru juga memiliki peran mengajar dan mendidik masyarakat agar menjadi warga negara Indonesia yang bermoral dan mencerdaskan kehidupan bangsa.

Penurunan kinerja guru ditunjukkan dengan kurangnya krativitas guru dalam menerapkan metode pembelajaran di kelas, praktek pembelajaran yang tidak sesuai dengan rencana pembelajaran di kelas, masih banyak guru yang belum memiliki lesson plan atau RPP. Sisi yang lain adalah masalah karakter disiplin pada guru yang lemah, misalnya masih ada guru yang suka keluar lingkungan sekolah tanpa maksud dan tujuan, masih adanya guru yang terlambat masuk sekolah, masih adanya guru yang sibuk memakai gadget pada saat mengajar untuk kepentingan pribadi.

Dengan kondisi yang dipaparkan mengenai penurunan kinerja guru maka ternyata masih banyak hal yang perlu dilakukan oleh kepala sekolah dalam meningkatkan dan menjaga kinerja guru agar tetap baik. Dalam upaya meningkatkan kinerja guru di sekolah, kepala sekolah harus sanggup memberikan bantuan kepada guru-guru agar para guru dapat mengerti dan menyadari pertama-tama adalah kelebihannya dan selanjutnya kekurangannya dalam ketreampilan mengajar. la harus mampu mendorong dan memotivasi guru untuk berkembang dalam kreativitas mengajarnya. Seorang kepala sekolah harus juga mau mendengar para guru-guru, dengan kebesaran hati mau menerima usulan-usulan dan masukan para guru dengan demikian tercipta suatu suasana dialog yang demokratis dan penuh kekeluargaan dalam upaya memajukan secara bersama pendidikan di sekolah.

Berdasarkan uraian diatas maka penelitian ini mengambil judul: "Peran Supervisi Kepala Sekolah Dalam Upaya Peningkatan Kinerja Guru di SMK Katolik Santo Yusup - Blitar."

\section{Supervisi - Kepala Sekolah (Principal - Supervision)}

Sergiovani dan starrat (1993:5) menyatakan bahwa: "supervision is process designed to help teacher and supervisor learn more about their practice; to better able to use their knowledge and skill to better serve parents and schools; and to make the school a more effective learning community." Supervisi adalah suatu proses yang dirancang untuk membantu guru dan supervisor belajar secara lebih jauh mengenai kegiatan yang mereka laksanakan; agar dapat menggunakan pengetahuan dan kemampuannya untuk memberikan layanan yang lebih baik 
kepada orang tua dan sekolah, serta berupaya menjadikan sekolah sebagai masyarakat belajar yang lebih efektif.

Sedangkan Sullivan dan Glanz (2009:4) berpendapat bahwa, "supervision is the process of engaging teacher in instructional dialogue for the purpose of improving teaching and increasing student achievement". Supervisi adalah proses pelibatan guru-guru dalam dialog pengajaran demi mengembangkan pembelajaran dan meningkatkan pencapaian murid.

Definisi Carlene Cassidy dan Robert Kreitner (2010:3) tentang supervisi melengkapi pemahaman umum kita. Mereka menuliskan bahwa, "Supervision is the first level of management in an organization and is concerned with encouraging the mambers of a work unit to contribute positively toward accomplishing the organization's goals and objectives". Supervisi adalah manajemen pada tingkatan dasar di dalam sebuah organisasi dan memiliki perhatian utama kepada kegiatan menyemangati anggota-anggota dari sebuah kelompok kerja agar mampu memberikan sumbangan yang positif kepada tujuan dan cita-cita organisasi.

Berdasarkan pendapat para ahli, dapat disintesiskan bahwa supervisi adalah sebuah proses kegiatan yang direncanakan untuk mengembangkan sumber daya manusia dalam sebuah organisasi dengan melibatkan semua pihak agar tujuan organisasi dapat tercapai dengan baik.

Ketika konsep supervisi dikaitkan dengan peran kepala sekolah sebagai supervisor maka supervisi - kepala sekolah dapat diartikan menjadi proses pengawasan yang dilakukan oleh pemimpin sekolah di sekolah untuk membantu atau membina guru secara terus menerus sehingga pembinaan ini menyebabkan perbaikan atau peningkatan kemampuan profesional guru.

\section{Kinerja Guru (Teacher Performance)}

Berman (2006:5) menggambarkan performance atau kinerja sebagai berikut, "...performance as the effective and efficient use of resources to achieve result". Kinerja merupakan pemakaian sumber daya secara efektif dan efisien untuk mencapai hasil. Lain halnya dengan Rue dan Byars (2010:291), bagi mereka, "performance refers to how well an employe is fulfilling the requirements of the job". Kinerja merujuk kepada bagaimana seorang karyawan menunaikan tuntutan kerja.

Bagi Robbin (2012:492) Kinerja dilihat juga sebagai hasil akhir dari sebuah aktivitas. Robbin menuliskan, "It's the end result of activity. And whether that activity is hours of intens practice before a concert or race or whether it's carrying out job responsibilities as efficiently and effectively as possible, performance is what results from that activity." Kinerja adalah hasil akhir dari aktivitas dan sekalipun aktivitas itu merupakan tindakan yang dilakukan berkali-kali sebelum acara konser atau perlombaan atau apapun itu, kinerja adalah hasil-hasil dari aktivitas itu.

Berdasarkan uraian di atas dapat disintesiskan bahwa kinerja atau performance adalah suatu kemampuan kerja atau prestasi kerja yang diperlihatkan oleh seorang pegawai untuk memperoleh hasil kerja yang optimal melalui hasil kerja, ketepatan waktu, inisiatif, kecakapan dan komunikasi yang baik.

Dalam kaitannya dengan peranan guru dalam lingkungan sekolah, maka yang dimaksud dengan teacher performance atau kinerja guru adalah hasil pekerjaan atau prestasi kerja yang ditunjukkan oleh seorang guru berdasarkan tuntutan kompetensi yang diminta, yaitu kompetensi pedagogik, kompetensi kepribadian, kompetensi sosial, dan kompetensi profesional.

\section{METODE PENELITIAN}

Penelitian ini merupakan penelitian kualitatif dengan pendekatan studi kasus untuk mengetahui bagaimana peran supervisi - kepala sekolah SMK Katolik Santo Yusup, Blitar, dalam upaya meningkatkan kinerja gurunya. Pendekatan penelitian dengan studi kasus dirasa cocok karena bermaksud mengungkap secara lebih mendalam sebuah fenomena unik yang 
nyata dan sedang berlangsung. Pendekatan ini dilandasi oleh pemikiran Robert K. Yin yang menuliskan bahwa studi kasus adalah suatu inkuiri empiris yang menyelidiki fenomena dalam konteks kehidupan nyata, bilamana batas-batas antara fenomena dan konteks tak tampak dengan tegas, dan di mana multi sumber bukti dimanfaatkan. Studi kasus lebih banyak berkutat pada atau berupaya menjawab pertanyaan-pertanyaan "how" (bagaimana) dan "why" (mengapa), serta pada tingkatan tertentu juga menjawab pertanyaan "what" (apa atau apakah), dalam kegiatan penelitian.

\section{HASIL PENELITIAN DAN PEMBAHASAN}

\section{Peran Kepala Sekolah Dalam Diagnosa Mengajar Guru}

Diagnosa adalah tindakan observasi dengan meneliti, mengamati, atau bertanya kepada para guru atau murid mengenai ada atau tidak adanya masalah mengajar guru dalam rangka melakukan perbaikan.

Berdasarkan pengamatan dan wawancara dengan kepala sekolah SMK Santo Yusup Blitar, dalam rangka diagnosa kinerja guru, kepala sekolah mengadakan inspeksi sebagai usaha mensurvei seluruh sistem Pendidikan yang ada. Survei ini berguna untuk menghimpun data yang aktual, bukan informasi yang kadaluwarsa, sehingga ditemukan masalah-masalah, kekurangan-kekurangan baik pada guru maupun murid, perlengkapan, kurikulum, tujuan Pendidikan, metode pengajaran, dan perangkat lain sekitar proses pembelajaran. Selain dengan melakukan inspeksi, kepala sekolah juga mengamati proses pembelajaran di kelas secara acak sambil membuka dialog dengan guru dengan komunikasi yang membangun dan menyenangkan. Permendiknas Nomor 35 Tahun 2010 tentang Juknis Penilaian Kinerja Guru menuliskan bahwa penilaian kinerja guru dilakukan di dalam kelas dan di luar kelas. Kegiatan yang tidak dapat di amati di dalam kelas misalnya penyusunan silabus, RPP, pengembangan kurikulum, tingkat kehadiran guru di kelas, praktik pembelajaran di luar kelas atau sekolah dan sebagainya, kesemuanya itu wajib melampirkan bukti-bukti yang berupa dokumen.

Dari hasil pengamatan kepala sekolah mendapatkan beberapa permasalahan yang perlu diperbaiki, diantaranya adalah karakter disiplin guru yang masih lemah dengan ditemukannya guru yang terlambat dan suka berada di luar lingkungan sekolah tanpa maksud dan tujuan yang jelas. Dari sudut keterampilan mengajar guru, ditemukanlah beberapa guru yang masih kesulitan dan kurang kreatif dalam menggunakan metode pembelajaran yang menyenangkan hal ini ditunjukkan dengan ditemukannya murid yang tidak betah di kelas dan berlama-lama di luar ruangan kelas. Situasi kelas yang ramai dan tak terkendali menunjukkan lemahnya guru dalam menggunakan metode pembelajaran yang menarik dan menyenangkan siswa. Temuan yang lain adalah bahwa banyak guru yang masih lemah dalam melengkapi administrasi guru yang menjadi pegangan atau sumber data pribadi untuk menilai dan mengevaluasi anak didiknya. Dari hasil temuan proses diagnosa langkah selanjutnya adalah mengolah dan menganalisa hasil informasi lapangan bersama-sama dengan tim supervisor.

Proses dignosa kepala sekolah SMK Katolik Santo Yusup Blitar ini senada dengan pemikiran beberapa ahli diantaranya adalah Hess seperti yang dikutip oleh Peter Hawkins dan Robin Shohet (2006:57) berpendapat bahwa: A quintessential interpersonal interaction with the general goal that one person, the supervisor, meets with another, the supervise, in an effort to make the later more effective in helping people. Dapat dijelaskan bahwa proses diagnosa dalam rangka peningkatan kinerja (performance) diwujudkan dalam bentuk sebuah interaksi interpersonal klasik antara supervisor dengan si penerima supervisi dalam usaha agar kedua belah pihak menjadi lebih efektif dalam tugasnya.

Hess dan Orthmann (2003:5) berpendapat sebagai berikut: Supervision is making sure the activities are effectively implemented by those responsible for doing so. Dapat dikatakan bahwa substansi dari diagnosa yang dilakukan oleh pimpinan atau kepala sekolah adalah sebuah tindakan untuk mengetahui dan memastikan guru atau karyawan mengerjakan tugas dan 
tanggung jawabnya dengan baik. Jika ditemukan hal-hal yang tidak berjalan dengan semestinya, hal itu menjadi masukan atau catatan untuk perbaikan.

Uraian diatas mengungkapkan bahwa peran kepala sekolah SMK Santo Yusup, Blitar dalam diagnosa adalah melakukan observasi lapangan dengan menerapkan semua jenis pendekatan yaitu pendekatan langsung, dimana yang berperan aktif adalah supervisor, pendekatan tidak langsung, dimana yang berperan aktif adalah guru dan pendekatan kolaboratif, dimana yang berperan aktif adalah supervisor dan guru. Penerapan semua metode pendekatan oleh kepala sekolah sangat mengakomodasi kebutuhan masing-masing guru sehingga proses supervisi menjadi sangat efektif dan efisien. Dalam hal ini Glickman (2010:7) mengatakan bahwa: "A paradigm shift toward the collegial model, if it is to succed, must include $s$ shift away from conventional or congenial supervision toward collegial supervision". Dari uraian di atas dapat dijelaskan bahwa pengawasan hendaknya ditandai dengan adanya relasi yang setara antara para guru dengan pengawas, pengawasan yang menitikberatkan kepada pengembangan keterampilan dan pengetahuan guru dalam pembelajaran, pengawas yang siap memberikan bantuan dalam menghadapi masalah serta memberikan alternatif jalan keluarnya.

\section{Peranan Kepala Sekolah Dalam Perbaikan Mengajar Guru}

Langkah perbaikan yang tepat tidak bisa dilakukan tanpa adanya kegiatan penilaian terhadap temuan permasalahan yang didapat dari hasil proses diagnosa. Kegiatan penilaian ini dimaksudkan untuk mengetahui faktor-faktor yang mempengaruhi situasi dan kondisi pendidikan serta pengajaran yang telah diteliti sebelumnya, kemudian dievaluasi untuk melihat bagaimana tingkat kualitas Pendidikan di sekolah itu, apakah menggembirakan atau memprihatinkan, mengalami kemajuan atau kemunduran, atau kemandegan. Penilaian tidak melulu kepada aspek negative saja tetapi juga aspek-aspek positif yang ditemukan.

Berdasarkan penelitian peran Kepala Sekolah SMK Katolik Santo Yusup Blitar dalam strategi perbaikan kinerja guru adalah dengan melakukan diskusi bersama atas temuan masalah yang berasal dari hasil observasi atau diagnosis lapangan. Kepala sekolah bersama-sama dengan tim supervisi yang dibentuk pada akhirnya memetakan masalah penyebab menurunnya kualitas kinerja guru menjadi dua hal, yaitu soal kurangnya penguatan karakter disiplin dan tanggung jawab dari guru di sekolah dan kurangnya skill atau ketrampilan mengajar guru dalam menerapkan metode pembelajaran di kelas.

Berdasarkan diskusi bersama dengan tim supervisi maka rekomendasi-rekomendasi yang diusulkan antara lain, untuk menguatkan karakter disiplin dan tanggung jawab guru di sekolah diusulkan supaya diselenggarakan latihan kepemimpinan dasar, lokakarya, seminar, dan retret tahunan. Selain itu diusulkan untuk menerapkan system reward dan punishment kepada semua guru dan karyawan dalam kaitannya dengan penegakkan disiplin. Berkaitan dengan aspek pengajaran yang masih kurang, rekomendasi yang muncul antara lain, pelatihan dalam bentuk on the job training, in house training, lokakarya, seminar, demonstrasi mengajar, simulasi, observasi, saling mengunjungi kelas. Sedangkan kriteria pemilihan program perbaikan sebagai berikut, yang pertama mengacu kepada asas kemendesakan, yang kedua mengacu kepada asas kebermanfaatan dan yang ketiga adalah menyangkut efisiensi pembiayaan.

Kepala sekolah bersama-sama dengan guru akhirnya memutuskan bahwa bentuk pembinaan yang diterapkan bagi perbaikan mengajar guru di SMK Santo Yusup, Blitar adalah: (I) Pembinaan Internal sekolah yang terdiri dari program In House Training, rapat kerja, pengarahan (directing) dari wakasek kurikulum atau kepala sekolah, mentoring, seminar; (2) Pembinaan Eksternal Sekolah yang terdiri dari program pelatihan tingkat kabupaten dan provinsi seperti ke VEDC Malang atau BLK Singosari, pendampingan IN on IN tentang kurikulum 2013 yang merupakan bagian dari IN House Training dan On Job Training di Politeknik Astra Jakarta.

Tindakan yang dilakukan oleh kepala sekolah SMK Santo Yusup sejalan dengan pemikiran dari Sullivan dan Glanz (2009:28) bahwa, "Bureau inspectional supervision should have 
no place in schools in the $2 I^{\text {st }}$ century. We must prepare supervisor who truly espouse participatory democratic values." Dari uraian ini dapat dijelaskan bahwa prinsip supervisi yang cocok pada masa kini dalam kepemimpinan sekolah adalah dengan prinsip saling mengembangkan antara guru dan supervisor, mengembangkan metode yang demokratis dan kooperatif, membangun sikap kepemimpinan, objektif, ilmiah yang berarti sistematis dan dilaksanakan secara tersusun demi terjadinya supervisi yang efektif dan efisien. Hal senada juga tercermin pada pendapat Gordon dalam Glickman dan Gordon (2010:7) bahwa, "Leadership is share with teacher, and it is cast in coaching, reflection, collegial investigation, study teams, exploration in to the uncertain, and problem solving”. Hal ini menunjukkan bahwa kepemimpinan modern, dalam hal ini kepala sekolah meminta kemampuan untuk berbagi dengan guru dalam pelatihan, refleksi, penyelidikan bersama, tim kerja, penjelajahan kepada hal yang belum tentu sampai pada penyelesaian masalah.

Dari uraian di atas dapat dikatakan bahwa peran Kepala sekolah dalam strategi perbaikan mengajar guru adalah dengan mencanangkan diskusi bersama dengan tim supervisi dan para guru atas temuan masalah dan mencari solusi yang tepat untuk menetapkan programprogram pembinaan sekolah yang dapat dilaksanakan dalam rangka upaya meningkatkan kinerja guru.

\section{Peran Kepala Sekolah Dalam Pembinaan Mengajar Guru}

Strategi pembinaan mengajar guru yang di maksudkan adalah upaya kepala sekolah dalam menstimulasi, mengarahkan, memberi semangat agar guru-guru mau menerapkan caracara baru yang diperkenalkan sebagai hasil upaya penemuan penelitian, termasuk dalam hal ini membantu guru-guru memecahkan kesulitan dalam menggunakan cara-cara baru teknik-teknik pengajaran. Oleh karena itu proses pembinaan juga perlu diiringi dengan monitoring oleh kepala sekolah sendiri beserta tim supervisi untuk memastikan terjadinya perbaikan pada guru binaan. Upaya pembinaan guru dilandasi juga oleh Undang-undang Nomor 14 Tahun 2005 Tentang Guru dan Dosen, Bab IV Bagian kelima pasal 32 tentang pembinaan dan pengembangan guru yang menyatakan bahwa pembinaan dan pengembangan guru meliputi pembinaan dan pengembangan profesi dan karir yang secara konkret mencakup: (I) proses menyusun program pembelajaran, yaitu: kurikulum, silabus, lesson plan atau RPP, program tahunan, program semester, rincian minggu efektif; (2) pembinaan pelaksanaan pembelajaran, yaitu: kegiatan membuka pelajaran, menjelaskan materi, media pembelajaran, metode pembelajaran, sumber belajar, dan Kriteria Ketuntasan Minimal (KKM); (3) pembinaan peningkatan kompetensi professional guru, yaitu: supervisi, penataran, seminar, dan Musyawarah Guru Mata Pelajaran (MGMP).

Berdasarkan penelitian peranan kepala sekolah dalam strategi pembinaan guru adalah dengan menerapkan secara konsekwen langkah-langkah perbaikan yang telah di sepakati dan direncanakan bersama, kepala sekolah bersama tim selalu siap (available) mendampingi guru yang masih kesulitan dalam menerapkan metode pembelajarannya, mengadakan evaluasi pembinaan dan sharing setiap semester secara berkelompok, pendampingan perseorangan oleh kepala sekolah, selalu memberikan motivasi dan dukungan positif kepada guru binaan, memberikan penghargaan sebagai pengakuan kepada guru yang memiliki prestasi kemajuan dalam disiplin dan keterampilan mengajar yang kreatif.

Dari uraian di atas dapat dikatakan bahwa langkah-langkah strategi pembinaan guru dalam upaya meningkatkan kemampuan mengajar guru sejalan dengan pemikiran Marzano (20II:2) yang menuliskan bahwa:"...the purpose of supervision should be the enhancement of teacher's pedagogical skill, with the ultimate goal of enhancing student achievement." Dapat dijelaskan bahwa tujuan dari supervisi seharusnya adalah peningkatan kualitas kemampuan pedagogis para guru (teacher performance) dengan pencapaian terakhir peningkatan kualitas pencapaian belajar murid. 
Dengan adanya bentuk penguatan seperti pendampingan, dukungan, dan reward dari kepala sekolah diharapkan memberikan dampak kepada peningkatan kinerja guru (teacher performance) dan hal ini juga sesuai dengan pendapat dari Luthan (201 I:406) yang menulis: "On the basis of the classic law of effect, or "Low of Behavior," reinforcement can be operationally defined as anything that increases the strength of a behavior and that tends to induce repetitions of the behavior that preceded the reinforcement." Dapat di katakan bahwa penguatan menjadi salah satu kunci dalam mempertahankan serta meningkatkan kinerja yang diharapkan oleh kepala sekolah dari guru.

Dari uraian di atas dapat disimpulkan bahwa peran kepala sekolah dalam strategi pembinaan kinerja guru adalah dengan menetapkan dan menjalankan program pembinaan secara konsekuen sesuai dengan kesepakatan dan perencanaan bersama, melakukan monitoring dan evaluasi terhadap berjalannya program pembinaan, dan memberikan penguatan yang menjamin peningkatan kinerja guru.

\section{KESIMPULAN}

Supervisi - kepala sekolah SMK Santo Yusup, Blitar dalam upaya meningkatkan kinerja guru memerlukan perencanaan yang matang agar mendapatkan dampak atau hasil yang berguna bagi peningkatan kinerja guru. Dalam penelitian ini penulis menyimpulkan tiga peran fundamental supervisi - kepala sekolah dalam upaya meningkatkan kinerja guru di SMK Santo Yusup, Blitar, yaitu: (I) Diagnosis atau identifikasi masalah kinerja guru. Dalam tahap ini kepala sekolah melakukan tindakan pengenalan masalah. Untuk mengetahui masalah yang ada pada kinerja guru maka perlu dilakukan penelitian dengan instrumen penelitian seperti angket, wawancara, kunjungan kelas, dan sebagainya. Setelah mendapatkan informasi yang memadai kepala sekolah kemudian memetakan permasalahan berdasarkan informasi yang telah diperoleh; (2) Peranan kepala sekolah dalam upaya perbaikan masalah mengajar guru. Pada tahap ini kepala sekolah menyelesaikan masalah yang ditemukan dengan diskusi dengan tim supervisi dan para guru yang berpengalaman agar memberikan pandangan, masukan atau input sehingga dapat dijadikan acuan dalam menyusun rekomendasi-rekomendasi sebelum menentukan rekomendasi yang paling cocok bagi penyelesaian masalah. (3) Melaksanakan langkah pembinaan dalam upaya meningkatkan kinerja guru. Pada tahap ini kepala sekolah menerapkan keputusan yang sudah diambil yang dirasa sangat perlu untuk segera dilaksanakan untuk menyelesaikan masalah mengajar guru. Upaya untuk memastikan bahwa implementasi dari penerapan pembinaan berjalan dengan baik dilakukan melalui proses monitoring dan dilanjutkan dengan evaluasi program pembinaan. Hasil evaluasi kemudian menjadi masukan kembali bagi kepala sekolah untuk mengevaluasi kembali efektivitas pilihan solusi bagi penyelesaian masalah.

\section{DAFTAR PUSTAKA}

Berman, Evan M. (2006). Performance and Productivity In Public And Non Profit Organization , 2nd ed. New York: ME. Sharpe.

Cassidy, Carlene dan Kreiter, Robert. (2010). Supervision: setting people up for success. Mason: South-Western.

Glickman, Carl D., P. Gordon, Stephen dan M. Ross-Gordon, Jovita. (2010). Supervision and Instructional Leadreship: a developmental approach. Boston: Pearson.

Hawkins, Peter and Shohet, Robin. (2006). Supervision in The Helping Professions. New York: McGraw - Hill.

Hess, K. dan Orthmann, C. (2003). Management and Supervision. New York: Delmar Cengage Learning.

Luthans, Fred. (20II). Organizational Behavior: an evidence-based approach. New York: McGraw Hill.

Jurnal Manajemen Pendidikan, Vol 10, No 2., 
Marzano, Robert J., Tont, dan Livingstone, David. (20II). Efective Supervision. Alexandria, Virginia: ASCD.

Rue dan Byars. (2010). Supervision. New York- McGRAW-HILL.

Robbins, S. P., and Judge, T. A. (20I2). Organizational Behavior. New Jersey: Pearson.

Sergiovanni, T. J., Starrat, R. J. (1993). Supervision: a redefinition. New York: McGraw-Hill.

Sergiovanni, Thomas J. (1996). Leadership For The Schoolhouse: how is it different? How is it important? San Francisco: Jossey-Bass Publishers.

Sullivan, Susan and Glanz, Jeffrey. (2009). Supervision That Improves Teaching And Learning. California: Corwin.

Yin, Robert K. (20I I). Qualitative Research From Start to Finish. New York: The Guilford Press. Undang-undang Republik Indonesia No. 14 Tahun 2005 tentang Guru dan Dosen.

Permendiknas Nomor 35 Tahun 2010 tentang Juknis Penilaian Kinerja Guru. 